九州大学学術情報リポジトリ

Kyushu University Institutional Repository

\title{
NONPARAMETRIC TESTS FOR SCALE
}

Tamura, Ryoj i

Shimane University

https://doi.org/10.5109/13020

出版情報: 統計数理研究. 12 (1/2)，pp. 89-94，1966-03. Research Association of Statistical Sciences

バージョン：

権利関係 : 


\title{
NONPARAMETRIC TESTS FOR SCALE
}

\author{
By
}

\section{Ryoji TAMURA}

(Received February 1, 1965)

We shall in this paper propose certain nonparametric test statistics for the scale problem which are essentially the same kind as Tamura [6]. Some of them have higher efflciency than Mood [2], Tamura [6], [7] and Sen [4] and one of them is very easy to apply practically.

Let $X_{1}, \cdots, X_{m}$ and $Y_{1}, \cdots, Y_{n}$ be the samples from the continuous c.d.f. $F(x-\xi)$ and $G(y)=F((y-\eta) / \theta)$ where $\xi$ and $\eta$ are respectively the population medians. We shall consider to test the hypothesis $H: \theta=1$ against the alternative $H^{\prime}: \theta>1$. Assume first that $\xi$ and $\eta$ are known, say zero without loss of generality. The auther has proposed the following in [6],

$$
Q_{N}=\left(\begin{array}{c}
m \\
2
\end{array}\right)^{-1}\left(\begin{array}{c}
n \\
2
\end{array}\right)^{-1} \sum \sum \phi\left(X_{\alpha_{1}}, X_{\alpha_{2}} ; Y_{\beta_{1}}, Y_{\beta_{2}}\right) \text {, }
$$

where

$$
\phi\left(x, x^{\prime} ; y, y^{\prime}\right)= \begin{cases}1 & \text { for } y<x, x^{\prime}<y^{\prime} \text { or } y^{\prime}<x, x^{\prime}<y \\ 0 & \text { otherwise }\end{cases}
$$

and the summations run over all subscripts $\alpha, \beta$ such that $1 \leqq \alpha_{1}<\alpha_{2} \leqq m$, $1 \leqq \beta_{1}<\beta_{2} \leqq n$.

Now we propose the following as a generalization of $Q_{N}$ (1),

$$
Q_{N, s}=\left(\begin{array}{c}
m \\
s
\end{array}\right)^{-1}\left(\begin{array}{c}
n \\
2
\end{array}\right)^{-1} \sum \sum \phi\left(X_{\alpha_{1}}, \cdots, X_{\alpha_{s}} ; Y_{\beta_{1}}, Y_{\beta_{2}}\right)
$$

where

$$
\phi\left(x_{1}, \cdots, x_{s} ; y^{\prime}, y\right)= \begin{cases}1 & \text { for } y<x_{1}, \cdots, x_{s}<y^{\prime} \text { or } y^{\prime}<x_{1}, \cdots, x_{s}<y \\ 0 & \text { otherwise }\end{cases}
$$

and the summations are over all subscripts $\alpha, \beta$ such that $1 \leqq \chi_{1}<\cdots<\alpha_{s} \leqq m$, $1 \leqq \beta_{1}<\beta_{2} \leqq n$.

Denoting the mean value of $Q_{N, s}$ by $\mu_{s}(\theta)$, then we get

$$
\mu_{s}(\theta)=2 \iint_{x^{\prime}<x}\left\{F(x)-F\left(x^{\prime}\right)\right\}^{s} d G(x) d G\left(x^{\prime}\right) .
$$

For later necessity, we compute the derivative of $\mu_{s}(\theta)$ at $\theta=1$,

$$
\left(\partial \mu_{s}(\theta) / \partial \theta\right)=2 \int_{\theta=1}^{\infty}\left[F^{s}(x)-\{1-F(x)\}\right] x f(x) d F(x) .
$$

As shown by Dwass [1], $\sqrt{N}\left(Q_{N, s}-\mu_{s}\right)$ is equivalent to the statistic 


$$
V_{N}=\frac{s}{V \lambda m} \sum_{i=1}^{m}\left\{\psi_{10}\left(X_{i}\right)-\mu_{s}\right\}+\frac{2}{\sqrt{(1-\lambda)}}=\sum_{j=1}^{n}\left\{\psi_{01}\left(Y_{j}\right)-\mu_{s}\right\}
$$

which is asymptotically normally distributed, where

$$
\begin{aligned}
& \psi_{10}\left(x_{1}\right)=E \phi\left(x_{1}, X_{2}, \cdots, X_{s} ; Y, Y^{\prime}\right), \lambda=m / N, N=m+n \\
& \psi_{01}(y)=E \phi\left(X_{1}, \cdots, X_{s} ; y, Y\right) .
\end{aligned}
$$

The asymptotic variance $\sigma_{s}^{2}(\theta)$ of $Q_{N, s}$ may be expressed by

$$
N \sigma_{s}^{2}(\theta)=\lambda^{-1} s^{2} \sum \operatorname{Var} \psi_{10}\left(X_{i}\right)+4(1-\lambda)^{-1} \sum \operatorname{Var} \psi_{01}\left(Y_{j}\right)
$$

In order to compute the value $\sigma_{s, 0}^{2}$ of $\sigma_{s}^{2}(\theta)$ under the hypothesis $H$, we first get the following

$$
\begin{aligned}
\psi_{10}(x) & =2 \operatorname{Pr}\left(Y<x, X_{2}, \cdots, X_{s}<Y^{\prime} \mid H\right) \\
& =2 \iint_{y<x<y^{\prime}}\left\{F\left(y^{\prime}\right)-F(y)\right\}^{s-1} d F(y) d F\left(y^{\prime}\right) \\
& =2 s^{-1}(1+s)^{-1}\left[1-F^{s+1}(x)-\{1-F(x)\}^{s+1}\right] .
\end{aligned}
$$

Thus we get

$$
\operatorname{Var} \psi_{10}(X)=8 s^{-2}(s+1)^{-2}\left[\frac{1}{2 s+3}-\frac{2}{(s+2)^{2}}+\frac{(s+1) !^{2}}{(2 s+3) !}\right]
$$

Similarly we get

$$
\operatorname{Var} \psi_{01}(Y)=2(s+1)^{-2}\left[\frac{1}{2 s+3}-\frac{2}{(s+2)^{2}}+\frac{(s+1) !^{2}}{(2 s+3) !}\right]
$$

Therefore it follows that

$$
\sigma_{s, 0}^{2}=\left(\frac{1}{m}+\frac{1}{n}\right) 8(s+1)^{-2}\left[\frac{1}{2 s+3}-\frac{2}{(s+2)^{2}}+\frac{(s+1) !^{2}}{(2 s+3) !}\right]^{(1)}
$$

By using (4) and (6), we may get the asymptotic efficiency $\boldsymbol{e}_{s}$ of the $Q_{N, s}$ test with regard to the $Q_{N, 1}$ test as follows,

$$
e_{s}=\frac{(s+1)^{2}}{360\left[\frac{1}{2 s+3}-\frac{2}{(s+2)^{2}}+\frac{(s+1) !^{2}}{(2 s+3) !}\right]}\left[\frac{\int_{-\infty}^{\infty}\left\{F^{s}-(1-F)^{s}\right\} x f d F}{\int_{-\infty}^{\infty}(2 F-1) x f d F}\right]^{2} .
$$

For $s=2$, which is corresponding to the $Q_{N}$ test (1), we get $e_{s}=1$. Namely it has been proved that the $Q_{N, 1}$ test is asymptotically equivalent to the $Q_{N}$ test. Assume that $F(x)$ be normal, then we get after some computations

$$
e_{s}=\frac{2 s+3}{10\left[s^{2}-2+\frac{(s+2) !^{2}}{(2 s+2) !}\right]}\left[\frac{E X_{1 s+2}^{2}-1}{E X_{13}^{2}-1}\right]^{2}
$$

, where $X_{1 s}$ expresses the smallest variable in the ordered sample of size $s$ from $N(0,1)$. The values may be computed by the Ruben's table [ 3$]$.

(1) This result has been suggested by Dr. N. Sugiura, Osaka University. 
Table

\begin{tabular}{ccc|c|c|cccccc|ccc|c}
\hline $\boldsymbol{s}$ & 2 & 3 & 4 & 5 & 6 & 8 & 10 & 12 & 14 & 15 & 16 \\
\hline $\boldsymbol{e}_{s}$ & 1 & 1.03 & 1.09 & 1.11 & 1.14 & 1.18 & 1.21 & 1.221 & 1.225 & 1.225 & 1.220 \\
\hline
\end{tabular}

In the case where medians are unknown, we again propose the similar statistic $\tilde{Q}_{N, s}$ as $\widetilde{Q}_{N}$ in $[6]$

$$
\tilde{Q}_{N, s}=\left(\begin{array}{c}
m \\
s
\end{array}\right)^{-1}\left(\begin{array}{c}
n \\
2
\end{array}\right)^{-1} \sum \phi\left(X_{\alpha_{1}}-\tilde{X}, \cdots, X_{\alpha_{s}}-\tilde{X} ; Y_{\beta_{1}}-\tilde{Y}, Y_{\beta_{2}}-\tilde{Y}\right)
$$

, where $\tilde{X}$ and $\tilde{Y}$ are sample medians.

From the Sukhatme's theorem [5], we define the following

$$
\begin{aligned}
& A_{s}\left(t_{1}, t_{2}\right)=E \phi\left(X_{1}-t_{1}, \cdots, X_{s}-t_{1} ; Y-t_{2}, Y^{\prime}-t_{2}\right) \\
& W_{s}\left(t_{1}, t_{2}\right)=\phi\left(X_{1}-t_{1}, \cdots, X_{s}-t_{1} ; Y-t_{2}, Y^{\prime}-t_{2}\right)-A_{s}\left(t_{1}, t_{2}\right) .
\end{aligned}
$$

First we prove that the partial derivatives of $A_{s}$ respective to $t_{i}$ vanish in $t_{1}=t_{2}=0$ under symmetric $F(x)$. Now

$$
\begin{aligned}
\left(\partial A_{s} / \partial t_{i}\right)_{t_{1}=t_{2}=0}= & (-1)^{i-1} 2 s \iint_{x<x^{\prime}}\left\{F\left(x^{\prime}\right)-F(x)\right\}^{s-1}\left\{f\left(x^{\prime}\right)-f(x)\right\} d G(x) d G\left(x^{\prime}\right) \\
= & (-1)^{i-1} 2 s\left[\iint_{x<x^{\prime}}\left\{F\left(x^{\prime}\right)-F(x)\right\}^{s-1} f\left(x^{\prime}\right) d G\left(x^{\prime}\right) d G(x)\right. \\
& \left.-\iint_{x<x^{\prime}}\left\{F\left(x^{\prime}\right)-F(x)\right\}^{s-1} f(x) d G\left(x^{\prime}\right) d G(x)\right] .
\end{aligned}
$$

In the second integration, we peform the translation $x=-y^{\prime}, x^{\prime}=-y$ and apply $F(x)=1-F(-x)$, then the second term is transformed as

$$
\iint_{y<y^{\prime}}\left\{F\left(y^{\prime}\right)-F(y)\right\}^{s-1} f\left(y^{\prime}\right) d G(y) d G(y) .
$$

Therefore it holds

$$
\left(\partial A_{s} / \partial t_{i}\right)_{t_{1}=t_{2}=0}=0 \text {. }
$$

It is remained to show

$$
E \mid W_{s}\left(t_{1}, 0\right)-W_{s}(0,0) \leqq M_{1} t_{1}, \quad E W_{s}\left(0, t_{2}\right)-W_{s}(0,0) \leqq \mathrm{M}_{2} t_{2}
$$

, where $M_{i}$ are constants. For this,

$$
\begin{aligned}
E W_{s}\left(t_{1}, 0\right) & -W_{s}(0,0) \leqq E \phi\left(X_{1}-t_{1}, \cdots, X_{s}-t_{1} ; Y, Y^{\prime}\right) \\
& -\phi\left(X_{1}, \cdots, X_{s} ; Y^{\prime}, Y\right)+A_{s}\left(t_{1}, 0\right)-A_{s}(0,0)
\end{aligned}
$$

Then

$$
\begin{aligned}
A_{s}\left(t_{1}, 0\right)-A_{s}(0,0) \leqq 2 s \iint_{-\infty}^{\infty} F\left(x^{\prime}+t_{1}\right)-F\left(x^{\prime}\right) \\
\quad-F\left(x+t_{1}\right)+F(x) d G(x) d G\left(x^{\prime}\right)
\end{aligned}
$$




$$
\begin{aligned}
& \leqq 4 s \int_{-\infty}^{\infty} F\left(x+t_{1}\right)-F(x) d G(x) \\
& \leqq 4 s a t_{1}
\end{aligned}
$$

if $f(x)$ is bounded in absolute value by $a$.

From the definition of $\phi$, we may also compute as follows,

$$
\begin{aligned}
E \phi & \left(X_{1}-t_{1}, \cdots, X_{s}-t_{1} ; Y, Y^{\prime}\right)-\phi\left(X_{1}, \cdots, X_{s} ; Y, Y^{\prime}\right) \\
& =\operatorname{Pr}\left\{\phi\left(X_{1}-t_{1}, \cdots, X_{s}-t_{1} ; Y, Y^{\prime}\right)=1 \text { and } \phi\left(X_{1}, \cdots, X_{s} ; Y, Y^{\prime}\right)=0\right\} \\
& +\operatorname{Pr}\left\{\phi\left(X_{1}-t_{1}, \cdots, X_{s}-t_{1} ; Y, Y^{\prime}\right)=0 \text { and } \phi\left(X_{1}, \cdots, X_{s} ; Y, Y^{\prime}\right)=1\right\} .
\end{aligned}
$$

The first probability is given by summations of the probabilities of the events of the following four types

(ii) $\quad Y^{\prime}-t_{1}<Y<X_{1}-t_{1}, \cdots, X_{s}-t_{1}<Y^{\prime}$

(iii) $\quad Y^{\prime}<X_{1}-t_{1}, \cdots, Y-t_{1}, \cdots, X_{s}-t_{1}<Y$

(iv) $Y-t_{1}<Y^{\prime}<X_{1}-t_{1}, \cdots, X_{s}-t_{1}<Y$.

The probability of the event (i) is transformed to the following

$$
\begin{gathered}
\sum_{r=0}^{s}\left(\begin{array}{l}
s \\
r
\end{array}\right) \iint_{x<x^{\prime}-t_{1}}\left\{F\left(x^{\prime}\right)-F\left(x+t_{1}\right)\right\}^{r}\left\{F\left(x^{\prime}+t_{1}\right)-F\left(x^{\prime}\right)\right\}^{s-r} d G(x) d G\left(x^{\prime}\right) \\
\quad \leqq \text { const. } \int_{-\infty}^{\infty}\left\{F\left(x+t_{1}\right)-F(x)\right\} d G(x) \leqq \text { const. at } .
\end{gathered}
$$

It is similarly shown that the other probabilities are smaller than const. $a t_{1}$. Thus the first half of (12) has been proved. The techniques are similar for the latter half. We may conclude that $\widetilde{Q}_{N, s}$ has the same asymptotic normal distribution as $Q_{N, s}$ by adding to (11) and (12) the property that $\sqrt{\boldsymbol{m}}(\tilde{X}-\xi)$ and $\sqrt{\boldsymbol{n}}(\tilde{Y}-\eta)$ are both bounded in probability.

\begin{tabular}{|c|c|c|c|}
\hline \multicolumn{2}{|c|}{$Q_{N, 2}$} & \multicolumn{2}{|c|}{$Q_{N, 1}$} \\
\hline ordering & $\begin{array}{l}\text { value of } \\
\left(\begin{array}{l}4 \\
2\end{array}\right)\left(\begin{array}{l}4 \\
2\end{array}\right) Q_{N, 2}\end{array}$ & ordering & $\begin{array}{l}\text { value of } \\
4\left(\begin{array}{l}4 \\
2\end{array}\right) Q_{N, 1}\end{array}$ \\
\hline $\begin{array}{c}Y Y X X X X Y Y \\
Y X Y X X X Y Y \\
Y Y X X X Y X Y \\
Y X X X X Y Y Y \\
Y Y Y X X X X Y \\
\vdots\end{array}$ & $\begin{array}{l}24 \\
18 \\
18 \\
18 \\
18\end{array}$ & $\begin{array}{c}Y Y X X X X Y Y \\
Y X Y X X X Y Y \\
Y Y X X X Y X Y \\
Y X X Y X X Y Y \\
Y Y X X Y X X Y \\
Y X Y X X Y X Y \\
\vdots\end{array}$ & $\begin{array}{l}16 \\
15 \\
15 \\
14 \\
14 \\
14\end{array}$ \\
\hline
\end{tabular}

Since it has been proved that the $Q_{N, 1}$ and $Q_{N, 2}$ tests are asymptotically equivalent, that is, they have the same asymptotic efficiency, their behaviours must be discussed in small sample. We cannot unfortunately deal with them in the general form, therefore we only check in the simple and special cases. When $m=n=4$, the orderings of $X$ 's and $Y$ 's which have larger values of $Q_{N, 2}$ or $Q_{N, 1}$ are respectively given as follows, 
Let the size $\alpha$ of test be $1 / 70$, then the critical regions contain both only an ordering $Y Y X X X X Y Y$ and therefore the tests have the equal powers. In the case $\alpha=5 / 70$, the critical regions are respectively constructed by the above five orderings (in the $Q_{N, 1}$ test, six in the randomized form). Since they have three in common, we may compare only the probabilities of the remainders. When $F(x)$ is symmetrical, it holds that

$$
\begin{aligned}
& \operatorname{Pr}(Y Y Y X X X X Y)=\operatorname{Pr}(Y X X X X Y Y Y), \\
& \operatorname{Pr}(Y X X Y X X Y Y)=\operatorname{Pr}(Y Y X X Y X X Y) .
\end{aligned}
$$

Now we assume that $F(x)$ be the uniform distribution in $(-1 / 2,1 / 2)$, then

$$
\begin{aligned}
& \operatorname{Pr}(Y X X X X Y Y Y)=\frac{4 !}{2 !} \int_{y_{1}<y_{2}}\left\{1-G\left(y_{2}\right)\right\}^{2}\left\{F\left(y_{2}\right)-F\left(y_{1}\right)\right\}^{4} d G\left(y_{1}\right) d G\left(y_{2}\right) \\
& =\frac{12}{\theta^{2}}\left\lceil\int_{1 / 2}^{\theta / 2}\left(\frac{1}{2}-\frac{y}{\theta}\right)^{2} d y_{2}\left\lceil\int_{-1 / 2}^{1 / 2}\left(\frac{1}{2}-y_{1}\right)^{4} d y_{1}+\int_{-\theta / 2}^{-1 / 2} d y_{1}\right\rfloor\right. \\
& \left.+\int_{-1 / 2}^{1 / 2}\left(\frac{1}{2}-\frac{y}{\theta}\right)^{2} d y_{2}\left\{\int_{-1 / 2}^{y_{2}}\left(y_{2}-y_{1}\right)^{4} d y_{1}+\int_{-\theta / 2}^{-1 / 2}\left(y_{2}+\frac{1}{2}\right)^{4} d y_{1}\right\}\right] \text {. }
\end{aligned}
$$

After some computations, we get

$$
\begin{aligned}
& \operatorname{Pr}(Y X X X X Y Y Y)=\underset{70 \theta^{4}}{1}\left[\frac{35}{2}(\theta-1)^{4}+28(\theta-1)^{3}\right. \\
& \left.+21(\theta-1)^{2}+8(\theta-1)+1\right] \text {. }
\end{aligned}
$$

From the similar computations,

$$
\begin{aligned}
& \operatorname{Pr}(Y X X Y X X Y Y)=\frac{1}{70 \theta^{4}}\left[21(\theta-1)^{3}+21(\theta-1)^{2}+8(\theta-1)+1\right], \\
& \operatorname{Pr}(Y X Y X X Y X Y)=\frac{1}{70 \theta^{4}}\left[14(\theta-1)^{2}+8(\theta-1)+1\right] .
\end{aligned}
$$

Under the alternative $\theta>1,(13)$ is larger than (14). Thus the power of the $\mathrm{Q}_{N, 2}$ test is larger than that of the $Q_{N, 1}$ test in this case. Consider the case $\alpha=17 / 252$ when $m=n=5$ and denote (power of $Q_{N, 2}$ test) - (power of $Q_{N, 1}$ test) by $d$. Then we may get the following by the similar considerations,

$$
d=\frac{5(\theta-1)^{2}}{336 \theta^{5}}\left[21(\theta-1)^{3}+63(\theta-1)^{2}+40(\theta-1)+6\right] .
$$

In this case it may also result the superiority of the $Q_{N, 2}$ test.

I should like to express my gratitude to Dr. N, Sugiura, Osaka University, for much help and criticism.

\section{References}

[1] Dwass, M. (1956). The large-sample power of rank order tests in the two sample problem. Ann. Math. Statist. 27. 352-374. 
[2] Mood, A. M. (1954). On the asymptotic efficiency of certain nonparametric two sample tests. Ann. Math. Statist. 26. 514-522.

[3] RUBEN, H. (1954). On the moments of order statistics in sampie from normal populations. Biometrika 41. 200-227.

[4] SEN, P. K. (1963). On weighted rank-sum tests for dispersion. A. I. S. M. 15. 117-135.

[5] Surнatme, B. V. (1958). Testing thc hypothesis that two populations differ only in location. Ann. Math. Statist. 29. 60-78.

[6] TAMURA, R. (1960). On the nonparametric tests based on certain U-statistics. Bull. Math. Statist. 9. 61-67.

[7] TAMURA, R. (1963). On a modification of certain rank tests. Ann. Math. Statist. 34. 1101-1103. 